\title{
Paradoxical carbon dioxide embolism during laparoscopic cholecystectomy as a cause of cardiac arrest and neurologic sequelae
} -a case report-

\author{
Hye Young Shin, Dong Wook Kim, Ju Deok Kim, Soo Bong Yu, Doo Sik Kim, Kyung Han Kim, and \\ Sie Jeong Ryu
}

Department of Anesthesiology and Pain Medicine, Kosin University College of Medicine, Busan, Korea

An 81-year-old male patient was scheduled for a laparoscopic cholecystectomy due to acute cholecystitis. About 50 minutes into the operation, the arterial blood pressure suddenly decreased and ventricular fibrillation appeared on the electrocardiography. The patient received cardiopulmonary resuscitation and recovered a normal vital sign. We suspected a carbon dioxide embolism as the middle hepatic vein had been injured during the surgery. We performed a transesophageal echocardiography and were able to confirm the presence of multiple gas bubbles in all of the cardiac chambers. After the operation, the patient presented a stable hemodynamic state, but showed weaknesses in the left arm and leg. There were no acute lesions except for a chronic cerebral cortical atrophy and chronic microvascular encephalopathy on the postoperative brain-computed tomography, 3D angiography and magnetic resonance image. Fortunately, three days after the operation, the patient's hemiparesis had entirely subsided and he was discharged without any neurologic sequelae. (Korean J Anesthesiol 2014; 67: 425-428)

Key Words: Carbon dioxide embolism, Cardiopulmonary resuscitation, Paradoxical embolism, Transesophageal echocardiography.

Received: June 19, 2014. Revised: 1st, July 18, 2014; 2nd, August 6, 2014. Accepted: August 22, 2014.

Corresponding author: Sie Jeong Ryu, M.D., Ph.D., Department of Anesthesiology and Pain Medicine, Kosin University College of Medicine, 262, Gamcheon-ro, Seo-gu, Busan 602-702, Korea. Tel: 82-51-990-6283, Fax: 82-51-254-2504, E-mail: siejeong@ns.kosinmed.or.kr (c) This is an open-access article distributed under the terms of the Creative Commons Attribution Non-Commercial License (http:// creativecommons.org/licenses/by-nc/3.0/), which permits unrestricted non-commercial use, distribution, and reproduction in any medium, provided the original work is properly cited. 
Nowadays, laparoscopic surgery is recognized as a general therapeutic method for abdominal surgery, which usually requires pneumoperitoneum by insufflating carbon dioxide $\left(\mathrm{CO}_{2}\right)$ gas into the abdominal cavity to facilitate surgical viewing and manipulation. Despite the advantages of laparoscopic surgery, it also presents some disadvantages and risks, such as bowel or vascular injury [1] and gas embolism [2]. Among them, venous gas embolism is not a frequent complication of laparoscopic surgery; however, a paradoxical $\mathrm{CO}_{2}$ embolism in which $\mathrm{CO}_{2}$ from the right heart flows into the left heart through the intracardiac or extracardiac shunt may have fatal consequences [3]. We herein report a case of a sudden cardiac arrest caused by a paradoxical $\mathrm{CO}_{2}$ embolism verified directly through a transesophageal echocardiography (TEE) in a patient undergoing a laparoscopic cholecystectomy.

\section{Case Report}

An 81-year-old male patient of $166 \mathrm{~cm}$ and $65 \mathrm{~kg}$ was scheduled for a laparoscopic cholecystectomy. The induction of the anesthesia was done with midazolam $1.5 \mathrm{mg}$, propofol $50 \mathrm{mg}$, remifentanil $60 \mu \mathrm{g}$, and rocuronium $50 \mathrm{mg}$. The anesthesia was maintained with $\mathrm{O}_{2} 1.5 \mathrm{~L} / \mathrm{min}$, air $2.5 \mathrm{~L} / \mathrm{min}$, sevoflurane $1.5-2.0 \mathrm{vol} \%$ and remifentanil $0.05-0.2 \mu \mathrm{g} / \mathrm{kg} / \mathrm{min}$. The patient was mechanically ventilated with a tidal volume (TV) of $500 \mathrm{ml}$ and a respiratory rate $(\mathrm{RR})$ of 10 rates/min. The end tidal $\mathrm{CO}_{2}$ partial pressure $\left(\mathrm{ETCO}_{2}\right)$ was $32 \mathrm{mmHg}$, and the peak airway pressure was 12 $\mathrm{cmH}_{2} \mathrm{O}$. During the operation, the monitoring of the patient included an electrocardiography, a noninvasive and invasive blood pressure (Philips IntelliVue MP40), a pulse oxymetry, and a bispectral index.

The laparoscopic cholecystectomy was initiated from a transperitoneal approach. A skin incision was made under the umbilicus to insert a Veress needle and $\mathrm{CO}_{2}$ was then insufflated to create a pneumoperitoneum with an intra-abdominal pressure of $14 \mathrm{mmHg}$. During the pneumoperitoneum, the fraction of inspired oxygen $\left(\mathrm{FIO}_{2}\right)$ was 0.5 , the TV was adjusted to 450 $\mathrm{ml}$, and the RR was adjusted to maintain the $\mathrm{ETCO}_{2}$ at 30-35 $\mathrm{mmHg}$. The patient was placed in the reverse Trendelenburg position with left tilting. Fifty minutes into the surgery, when the surgeon controlled the bleeding in the dissected area, the systolic blood pressure (SBP) decreased rapidly from 130 to $70 \mathrm{mmHg}$, the heart rate (HR) increased from 90 to 140 beats/min and the $\mathrm{ETCO}_{2}$ dropped from 35 to $13 \mathrm{mmHg}$, although the peripheral $\mathrm{O}_{2}$ saturation $\left(\mathrm{SpO}_{2}\right)$ was maintained at $100 \%$. Despite a prompt injection of phenylephrine $100 \mu \mathrm{g}$, the SBP further dropped under $50 \mathrm{mmHg}$. Subsequently, the arterial pulse wave disappeared (the $\mathrm{SpO}_{2}$ was not checked), and the cardiac rhythm was converted from sinus tachycardia to ventricular fibrillation. We asked the surgeon to stop the operation and the $\mathrm{CO}_{2}$ insuffla- tion, and immediately initiated chest compression. At the same time, $100 \% \mathrm{O}_{2}$ was supplied, and epinephrine $1 \mathrm{mg}$ was injected twice intravenously. Then, defibrillation was performed using a biphasic defibrillator (150 J), and amiodarone $300 \mathrm{mg}$ was injected intravenously. The cardiac rhythm reverted to a sinus rhythm, and the BP and HR were recovered at 120/80 $\mathrm{mmHg}$ and 140 beats/min respectively following the cardioversion. The arterial blood gas analysis (ABGA) at that time showed $\mathrm{pH} 7.06$, arterial $\mathrm{O}_{2}$ partial pressure $\left(\mathrm{PaO}_{2}\right) 222 \mathrm{mmHg}$, arterial $\mathrm{CO}_{2}$ partial pressure $\left(\mathrm{PaCO}_{2}\right) 71 \mathrm{mmHg}$, base excess $-10.2 \mathrm{mmol} / \mathrm{L}$, and arterial $\mathrm{O}_{2}$ saturation $\left(\mathrm{SaO}_{2}\right) 100 \%$. It took less than 15 minutes to achieve full recovery of the vital signs. Although the blood pressure was incidentally decreased, the SBP was maintained above $100 \mathrm{mmHg}$ with a rapid intravenous fluid infusion of plasmalyte (1 L for 20 minutes) and a dopamine $10 \mu \mathrm{g} / \mathrm{kg} / \mathrm{min}$ and phenylephrine $0.8 \mu \mathrm{g} / \mathrm{kg} / \mathrm{min}$ infusion.

Considering the possibility of a middle hepatic vein injury during the gallbladder dissection and intra-operative monitoring review of the patient, we assumed a $\mathrm{CO}_{2}$ gas embolism as the underlying condition. TEE monitoring was initiated and it revealed diffuse gas bubbles in the cardiac chamber in the midesophageal right ventricle inflow-outflow view (Fig. 1). The midesophageal 5 chamber view provided a closer look at the gas bubbles in the left atrium, the left ventricle, and the aorta (Fig. 2). To prevent a cerebral embolism, we left the patient in the Trendelenburg position and aspirated the blood through a central venous catheter in the right internal jugular vein which had been inserted during the CPR. Although some gas bubbles remained in the cardiac chamber, the vital sign was stable, at $\mathrm{SpO}_{2} 100 \%$ and $\mathrm{ETCO}_{2} 32$ to $38 \mathrm{mmHg}$. The operation was resumed with open surgery for the repair of the injured vessels and the patient

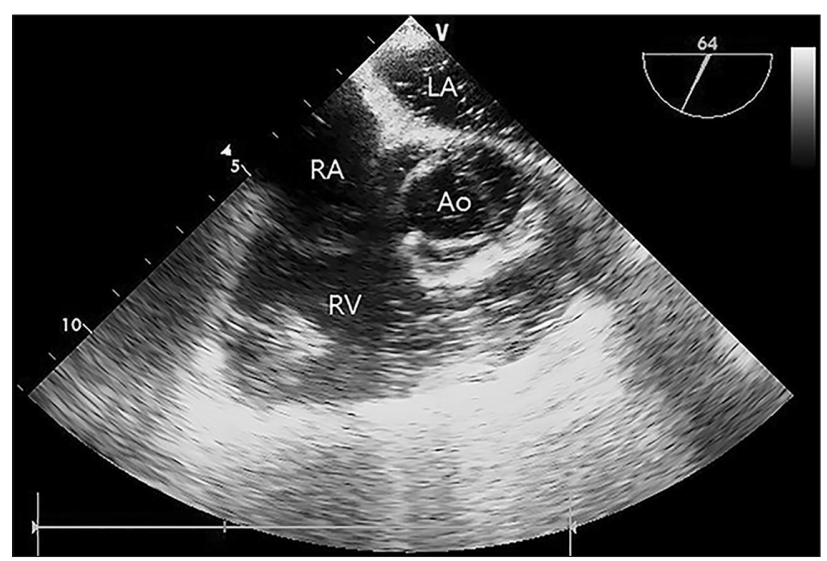

Fig. 1. Midesophageal right ventricle inflow-outflow view of the transesophageal echocardiography immediately after the cardiopulmonary resuscitation showing a considerable amount of air bubbles accumulated in the right-side heart, especially in the right ventricular outflow tract. $\mathrm{RV}$ : right ventricle. 


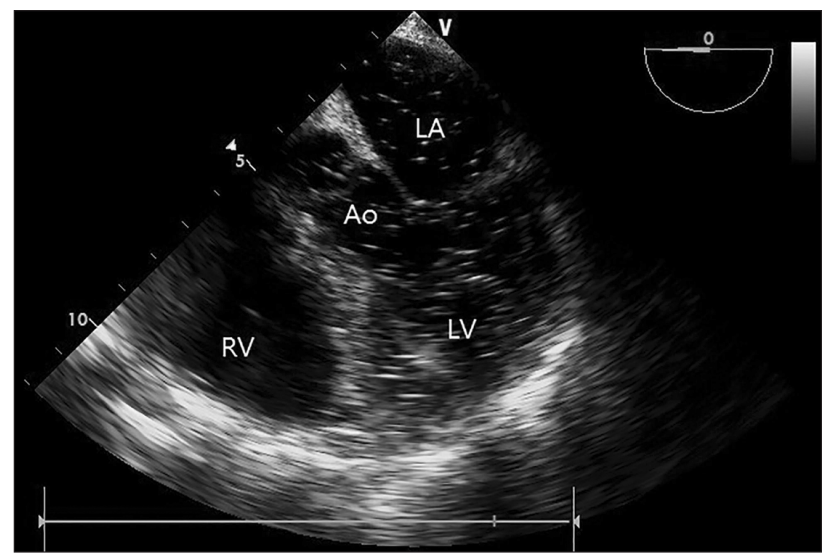

Fig. 2. Midesophageal 4 chamber view immediately after the cardiopulmonary resuscitation showing disseminated air bubbles in the leftside heart, including the aorta, left ventricle and atrium. Ao: aorta, LA: left ventricle; and LV: left ventricle.

was maintained in the Trendelenburg position to limit the risk of a cerebral embolism. Thirty minutes after the operation was resumed, the ABGA read $\mathrm{pH} 7.35, \mathrm{PaO}_{2} 204 \mathrm{mmHg}, \mathrm{PaCO}_{2} 42$ $\mathrm{mmHg}$, base excess $-2.4 \mathrm{mmol} / \mathrm{L}$, and $\mathrm{SaO}_{2} 100 \%$. At the same time, the amount of gas bubbles on the TEE had declined gradually, and almost no gas bubble remained in the cardiac chamber (Fig. 3). One hour later, the full surgical procedure was completed. After extubation, the patient could breathe spontaneously $\left(100 \% \mathrm{O}_{2}\right)$ without any problem. However, he was eventually transported to the intensive care unit owing to disorientation as to his name and place. Although this was fully recovered within one hour, weaknesses of his left arm and leg (3/5 strength grade) appeared on his physical examination. The computed tomography, 3D angiography, and magnetic resonance image showed only a chronic cerebral cortical atrophy and chronic microvascular encephalopathy, without any acute lesion. On postoperative day (POD) 2, the patient's muscular strength had improved to $4 / 5$ and was completely recovered as $5 / 5$ by POD 3 . The patient was transported to a ward on POD 5 and he was discharged on POD 10 without any complications or sequelae.

\section{Discussion}

Due to the use of $\mathrm{CO}_{2}$ to create a pneumoperitoneum during laparoscopic surgery, a $\mathrm{CO}_{2}$ embolism may be induced. Gas emboli entrapped by an injured vessel can flow into the heart so that they interrupt the right ventricular ejection, resulting in sudden systemic hypotension, pulmonary hypertension, and arrhythmia [4]. However, an inflow of $\mathrm{CO}_{2}$ into the systemic circulation does not always cause such clinical symptoms [5]. The latter are attributable to a characteristic of the $\mathrm{CO}_{2}$ which is easily dissolved in the plasma (the $\mathrm{CO}_{2}$ solubility in the plasma is $0.416 \mathrm{mmol} / \mathrm{L} / \mathrm{kPa}$ at $15^{\circ} \mathrm{C}$ ) [6]. Moreover, a small amount of

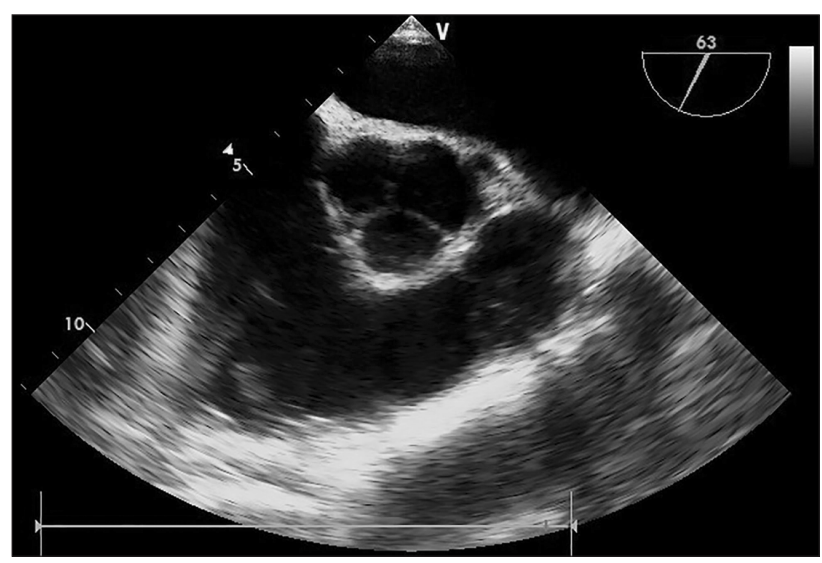

Fig. 3. Midesophageal right ventricle inflow-outflow view of the transesophageal echocardiography $30 \mathrm{~min}$ after the cardiopulmonary resuscitation showing the disappearance of all the air bubbles previously accumulated in the right side heart.

$\mathrm{CO}_{2}$ does not have a significant effect on the systemic circulation. If a gas embolism is created, the clinical symptoms and degree of the hemodynamic impact of the gas embolism depend on the bubble size and amount or speed of the intravenous administration of the gas [7]. In laparoscopic cholecystectomy, although gas emboli have been observed in $4 / 20$ patients during the $\mathrm{CO}_{2}$ insufflation and in 20/20 patients during the gallbladder dissection, no significant changes in the cardiorespiratory variables have been observed [8]. In this case, it is unlikely that the $\mathrm{CO}_{2}$ embolism occurred from the creation of the pneumoperitoneum via the trocar, as the patient did not show abnormal signs during the first 50 minutes of the operation. The gallbladder was severely inflammated and adhered to adjacent tissue. Therefore, time was spent to dissect the gallbladder and the oozing was not easily controlled. During the dissection of the gallbladder, the surgeon suspected an injury of the vessel. Although the surgeon tried to control the bleeding by gauze compression and electrocoagulation, an additional vessel injury occurred. Thereafter, the SBP and $\mathrm{ETCO}_{2}$ suddenly dropped. The partially-damaged terminal portion of the middle hepatic vein had a high probability of causing a $\mathrm{CO}_{2}$ embolism. It resulted from the process that the blood vessels and the adjacent tissues were detached for adhesiolysis. Although the surgeon was not overly concerned as the oozing was only mild and the vital sign was stable at the time, the $\mathrm{CO}_{2}$ must have flowed in through the damaged vessel. In cases of injury of the terminal portion of the middle hepatic vein, the surgeons cannot identify the vessel injury easily as the intravenous pressure is too low to induce active bleeding. The increased intra-peritoneal pressure from the pneumoperitoneum served as a driving force for the $\mathrm{CO}_{2}$ to rapidly enter the blood vessel [9].

Meanwhile, TEE is useful in detecting and monitoring intracardiac air bubbles and a massive $\mathrm{CO}_{2}$ embolism, but it is not 
good for detecting the $\mathrm{CO}_{2}$ flow into a vein. In general, the gas bubbles entrapped by the injured vein remain in the right atrium and ventricle. In this case, we observed $\mathrm{CO}_{2}$ gas bubbles in the left atrium and ventricle (a paradoxical embolism). There are two mechanisms for a paradoxical embolism. First, the gas bubbles in the right heart are transported to the left heart through the right-to-left shunt, which leads to a paradoxical embolism. Specifically, an intracardiac shunt is caused by a cardiac structural defect such as a patent foramen ovale (PFO), atrial septal defect, or ventricular septal defect [10]. A Valsalva maneuver to increase the right atrial pressure may be a useful method to open the PFO [11], but we did not attempt this maneuver because of our concern for hemodynamic instability. Second, the gas bubbles in the right heart move to the left heart through the pulmonary circulation [12]. When the gas bubbles flow in at a rate exceeding the filtering capacity of the lungs, the gas bubbles can be transported to the left heart by the lungs. Our patient did not show any structural defect such as a PFO on the pre-, postoperative transthoracic echocardiography, and intra-operative TEE. Therefore, the $\mathrm{CO}_{2}$ bubbles must have been transported to the left heart through the pulmonary circulation. Furthermore, in a paradoxical $\mathrm{CO}_{2}$ embolism, the gas bubbles ejected from the left ventricle can easily be transported to the cerebral vessel, which can cause an ischemic injury of the brain. In our case, although weakened muscular strength was found postoperatively in the patient's left arm and leg, his cerebral imaging tests showed no specific findings and, fortunately, his muscle power was fully recovered within a few days. This result seemed to be derived from the high solubility of the $\mathrm{CO}_{2}$ in the blood and the prompt interruption of the pneumoperitoneum immediately after the event to prevent an additional $\mathrm{CO}_{2}$ insufflation [13]. If an intra-operative $\mathrm{CO}_{2}$ embolism is suspected, the $\mathrm{CO}_{2}$ insufflation should be stopped immediately and the patient placed in the Durant position (head down and left lateral decubitus). Hyperventilation with $100 \% \mathrm{O}_{2}$ and a massive fluid infusion may be helpful to decrease the risk of embolism [14].

In conclusion, gas emboli are frequently developed during gallbladder dissections in laparoscopic cholecystectomies, even though the cardiorespiratory insult may be minimal. However, as this case evidences, surgeons should always consider the risk of a $\mathrm{CO}_{2}$ embolism during a laparoscopic surgery. Anesthesiologists should therefore diligently monitor the patient's hemodynamic state for early detection of $\mathrm{CO}_{2}$ emboli, and communication with the surgeon may be necessary in specific situations to obtain information regarding the surgical field.

\section{References}

1. Vallancien G, Cathelineau X, Baumert H, Doublet JD, Guillonneau B. Complications of transperitoneal laparoscopic surgery in urology: review of 1,311 procedures at a single center. J Urol 2002; 168: 23-6.

2. Cottin V, Delafosse B, Viale JP. Gas embolism during laparoscopy: a report of seven cases in patients with previous abdominal surgical history. Surg Endosc 1996; 10: 166-9.

3. Uchida S, Yamamoto M, Masaoka Y, Mikouchi H, Nishizaki Y. A case of acute pulmonary embolism and acute myocardial infarction with suspected paradoxical embolism after laparoscopic surgery. Heart Vessels 1999; 14: 197-200.

4. Kim HT, Kim KY, Park IB, Lee MJ. Air embolism during anesthesia in the beach chair position for shoulder surgery. Anesth Pain Med 2010; 5: $142-5$.

5. Derouin M, Couture P, Boudreault D, Girard D, Gravel D. Detection of gas embolism by transesophageal echocardiography during laparoscopic cholecystectomy. Anesth Analg 1996; 82: 119-24.

6. Lumb AB. Carbon dioxide. In: Nunn's Applied Respiratory Physiology. 7th ed. Edinburgh, Churchill Livingstone. 2010 , p 160.

7. Mayer KL, Ho HS, Mathiesen KA, Wolfe BM. Cardiopulmonary responses to experimental venous carbon dioxide embolism. Surg Endosc 1998; 12: 1025-30.

8. Park SH, Park CH, Song JE, Kim SH, Lee JY, Kim MH. Transesophageal echocardiographic assessment of venous carbon dioxide embolism during laparoscopic cholecystectomy. Korean J Anesthesiol 2006; 50: 20-4.

9. Schmandra TC, Mierdl S, Bauer H, Gutt C, Hanisch E. Transesophageal echocardiography shows high risk of gas embolism during laparoscopic hepatic resection under carbon dioxide pneumoperitoneum. Br J Surg 2002; 89: 870-6.

10. Lee YS, Choi SE, Park SW, Kim KS. Paradoxical air embolism due to electrosurgical vaporization during hysteroscopic myomectomy. Korean J Anesthesiol 2012; 62: 293-4.

11. Greim CA, Trautner H, Krämer K, Zimmermann P, Apfel CC, Roewer N. The detection of interatrial flow patency in awake and anesthetized patients: a comparative study using transnasal transesophageal echocardiography. Anesth Analg 2001; 92: 1111-6.

12. Bedell EA, Berge KH, Losasso TJ. Paradoxic air embolism during venous air embolism: transesophageal echocardiographic evidence of transpulmonary air passage. Anesthesiology 1994; 80: 947-50.

13. Kulkarni GV, Fisichella PM, Jericho BG. Suspected cerebral arterial gas embolism during a laparoscopic Nissen fundoplication. World J Anesthesiol 2013; 2: 26-9.

14. Park EY, Kwon JY, Kim KJ. Carbon dioxide embolism during laparoscopic surgery. Yonsei Med J 2012; 53: 459-66. 